\title{
Regulating for Innovation? \\ Insights from the Finnish Presidency of the Council of the European Union
}

\begin{tabular}{|r|l|}
\hline Journal: & European Journal of Risk Regulation \\
\hline Manuscript ID & EJRR-19-0065.R1 \\
\hline Manuscript Type: & Report \\
\hline Keywords: & Innovation Principle, EU Agenda, Finnish Presidency \\
\hline \multicolumn{2}{l}{} \\
\hline
\end{tabular}

\section{SCHOLARONE ${ }^{\text {M }}$ \\ Manuscripts}




\section{Regulating for Innovation? \\ Insights from the Finnish Presidency of the Council of the European Union}

\section{Introduction}

Should the European Union (EU) take into account the impact on research and innovation while developing or updating policy? According to the European Council the answer is positive. In May 2016 in fact the Council supported the innovation perspective in the regulatory process following a policy debate on how to tweak the better regulation strategy of the European Union in order to strengthen competitiveness ${ }^{1}$. The same idea of using regulatory policy to support innovation, competitiveness and growth appeared in a 2016 staff working paper of the European Commission ${ }^{2}$. The Commission Industrial Policy Strategy ${ }^{3}$ refers more precisely to the Innovation Principle (IP), thus upgrading the 'perspective' on innovation to a principle, that is, a foundation of regulatory and policy choice. The same IP is found in the law establishing European Horizon ${ }^{4}$. Innovation is also mentioned in the better regulation toolkits of the Commission \#20 and \#21 here as inclusion of elements of innovation in the Impact Assessment process.

Granted that there are no objections to innovation as important means to the ends of competitiveness and growth, the political question is whether the EU is now poised for embracing the IP as foundation of regulatory and policy choice. In a few words: innovation can be a policy perspective of 'frame of reference' for policies, a binding or non-binding principle. Where does the new Commission stand? And is this the same position adopted by the Council? What is the new agenda about it and does it re-define the relation between innovation and the Treaty-based precautionary principle?

Some of these points were addressed during the Innovation Principle Conference held in Helsinki on 3 December 2019 where a wide group of policy makers, experts, academics, innovators as well as NGOs and students gathered to discuss about innovation and regulation. The aim of the conference was to uncover the potential, and to some extent the problems, of the IP and to assess how a regulatory framework could better address challenges such as new technologies and environmental goals.

The conference was the most recent episode of a discussion on innovation as possible foundation of regulatory choice in the EU that comprehends scholarly works on innovation principle ${ }^{5}$, innovation and legislation as well as new regulatory challenges ${ }^{6}$. In particular, given the quite recent advent of the IP within

\footnotetext{
${ }^{1}$ European Council 2016 'Better regulation to strengthen competitiveness' 26 May 2016, press release https://www.consilium.europa.eu/en/press/press-releases/2016/05/26/conclusions-better-regulation/

${ }^{2}$ See the Commission Staff Working Document 'Better Regulations for innovation-driven investments at EU level' ${ }^{3}$ European Commission, 13 September 2017, 'Investing in a Smart Innovative and sustainable industry. A renewed industrial policy strategy’ Accessed 17 December 2019 https://eur-lex.europa.eu/legalcontent/EN/TXT/?uri=COM:2017:0479:FIN

${ }^{4}$ European Parliament, text adopted 'Establishing Horizon Europe' accessed 17 December 2019

http://www.europarl.europa.eu/doceo/document/TA-8-2019-0395_EN.pdf

${ }^{5}$ In particular, for scholarly works on innovation principle see Aurelien, Portuese and Julien Pillot, 'The Case for an Innovation Principle: A Comparative Law and Economics Analysis' (2018) 15 Manchester Journal of International Economic Law 2014,

${ }^{6}$ Scholarly works on Innovation and legislation include among others works on legal and regulatory problems on the technological frontiers: see for instance Bennett Moses 2015 'How to Think about Law, Regulation and Technology: Problems with Technology as a regulatory target' Law Innovation and Technology, 5:1, 1-20. A reflection on how legislation can become more adaptable to innovation is provided in Ranchordas, Sofia and van 't Schip, Mattis, 'Future-
} 
the EU scholars have suggested looking at the tension between innovation-driven economic objectives and the limits of innovation in terms, for instance, of environmental protection and sustainable development ${ }^{7}$. With the Juncker Commission the IP made progress in the EU in two important ways. First, as mentioned above, it was officially discussed and endorsed by the Council of Competitiveness Ministers. On 26 May 2016 the Conclusions of the Competitiveness Council reported that the IP "entails taking into account the impact on research and innovation in the process of developing and reviewing regulation in all policy domains". Specifically, the Council called "on the Commission together with Member States to further determine its use and evaluate its potential impact". The conference in Helsinki was a way to follow up on this request.

In the previous Commission, it was Commissioner Moedas to insist on linking regulatory policy (the better regulation strategy in particular) to innovation - as mentioned, the key document was Better Regulations for Innovation-Driven Investment ${ }^{10}$. This document argues that better regulation should be re-shaped to become a policy for innovation. Always within the Commission, its in-house think tank, the European Political Strategy Centre (EPSC) ${ }^{11}$, developed the connection between regulation and innovation in a note on Towards an Innovation Principle Endorsed by Better Regulation. For the EPSC the innovation principle is "a positive obligation to facilitate innovation" 12 . Central in the EPSC thinking is the concept that regulation ought to ensure "the appropriate framework conditions to foster entrepreneurship and a culture of innovation"13. This means cutting regulation when it hinders innovation; solving problems that markets cannot handle alone; and providing a policy paradigm which fosters human needs and meets global challenges ${ }^{14}$. The EPSC made the claim that innovation is a political and legal principle. In making the case for innovation as legal and political principle, the EPSC goes back to freedom of sciences (art.13 of the EU Charter of Fundamental Rights), art.3 of the TFEU (the EU 'shall promote scientific and technological advance) and art. 173 TFEU that explicitly mentions innovation in the context of industrial policies. This claim is the strongest possible declination of innovation. It is a claim for innovation as political and legal principle. This is an argument even stronger than the original articulation of the IP, which appeared first on the EU agenda thanks to the activity of the European Risk Forum. Not even the founding thinkers of the IP at the ERF had thought of giving the IP legal and political "foundational" status. This legal and political upgrading of the IP has naturally raised the objections of the advocacy group Corporate Europe Observatory ${ }^{15}$.

The balance with Precaution and contrasts with 'One in, one out'

Proofing Legislation for the Digital Age' (August 8, 2019) in S. Ranchordas and Y. Roznai (Eds), Time, Law, and Change (Hart, 2020, Forthcoming).

${ }^{7}$ Kathleen Garnett, Gert Van Calster \& Leonie Reins (2018) 'Towards an innovation principle: an industry trump or shortening the odds on environmental protection?' Law, Innovation and Technology, 10:1, 1-14

${ }^{8}$ Council of the EU, 2016

${ }^{9}$ Ibid.

${ }^{10}$ European Commission, 2016 'Better Regulation for innovation-driven investment at EU level' accessed 17 December $2019 \mathrm{https}$ ://op.europa.eu/en/publication-detail/-/publication/404b82db-d08b-11e5-a4b5-01aa75ed71a1/languageen/format-PDF/source-79728021

${ }^{11}$ See the description of EPSC at https://ec.europa.eu/epsc/about.en accessed 17 December 2019

${ }^{12}$ European Political Strategy Centre, 2016 Towards an Innovation Principle Endorsed by Better Regulation. EPSC Strategic Notes.

${ }^{13}$ Ibid.

${ }^{14}$ Charles Edquist (2017) Striving Towards a Holistic Innovation Policy in European Countries - But Linearity Still Prevails! STI Policy Review 5:2.

${ }^{15}$ Corporate Europe Observatory, 'Innovation Principle' accessed 17 December 2019: https://corporateeurope.org/en/2019/12/finnish-presidency-dedicates-high-level-conference-innovation-principlepushed-corporate 
For all the enthusiasm surrounding the IP, however, the fact remains that both the Competitiveness Council and the EPSC argue that the innovation principle has to be balanced with another foundation of regulatory choice: the precautionary principle. The Precautionary Principle (PP) was adopted in 2001 and is detailed in Article 191(TFEU), it relates to an approach of risk management that maintains that whether there is the possibility that a policy might cause harm the policy should not be pursued ${ }^{16}$. The ERF as mentioned coined the IP - arguing that it was complementary to the Precautionary Principle (PP) ${ }^{17}$. According to the ERF the IP and PP should be balanced with one another taking into account scientific integrity and accounting for indirect and regulatory impacts. In the ERF we find the original and clearest formulation of the IP: the principle states that "whenever policy or regulatory decisions are under consideration, the impact on innovation should also be fully assessed and addressed". There is no mention of precaution, hence for the ERF the IP was less a counter-principle (countering precaution) and more a level for the competitiveness of a sluggish European economy. The Centre for European Policy Studies (CEPS) too argue that the two principles, innovation and precaution, should complement each other ${ }^{18}$.

The IP is not the only addition in the EU regulatory framework. The new Commission has introduced in its working methods a novel principle to be applied in every legislative proposal: the 'one in, one out' (OIOO) approach. The 'one in, one out' is a principle that is set to reduce the legislative burden by eliminating existing rules for everyone created by new legislative proposals, it will be overseen by the Vice-President for Interinstitutional Relations and Foresight, and will be a commitment of the new College to deliver the President of the Commission's Agenda for Europe.

OIOO is not necessarily in contrast with the IP. But it is a very different principle. It is a case of regulatory offsetting, not a perspective or a principle oriented towards final goals. Most importantly OIOO is now part of the Working Method of the Commission while the IP is not. It remains to be seen what the connection is between OIOO and IP - if any.

In particular, concerns appear on the complementarity of the OIOO approach with the IP vision. Regulatory offsetting of the type of OIOO is miles apart from the logic of regulating for innovation. OIOO is a political commitment that challenges the technical layers of the Commission. The report from the Consultant ${ }^{19}$ commissioned by German Ministry for Economic Affairs and Energy is supposed to facilitate the transition from the political to the technical level. The technical challenge is eminently for the Secretariat-Geneneral and the RSB - the latter is now compelled to scrutinize the Impact Assessments (IAs) taking OIOO in consideration. According to the RSB, OIOO is not going to be interpreted technically as push for deregulation. It will be applied "in an intelligent way", moreover - the RSB argument goes on - regulations coming from the EU will be assessed against sustainability, this practically means to assess how many regulations already exist and whether a new regulation will be sustainable for the future. In other words, in every new proposal the collective effort is to push the sustainability principle forward and the regulation will follow.

The New Agenda: Responsive Innovation and Citizens Engagement.

The Helsinki Conference chose the angle of 'responsible innovation' in approaching the theme of IP and regulation. It seems in fact that one way to resolve some of the ambiguity and tension around the IP is to take

\footnotetext{
${ }^{16}$ See the complete definition of Precautionary Principle, accessed 17 December 2019 https://eurlex.europa.eu/summary/glossary/precautionary principle.html

${ }^{17}$ ERF (2011) The Precautionary Principle. Application and Way forward. Acessed 17 December 2019 http://www.riskforum.eu/uploads/2/5/7/1/25710097/erf pp way forward booklet.pdf

${ }^{18}$ Jose Manuel Leceta, Andrea Renda, Totti Könnölä, Felice Simonelli(2017) Unleashing Innovation and Entrepreneurship in Europe, People Places and Policies. CEPS http://aei.pitt.edu/84485/1/TFR_Innovation_final.pdf

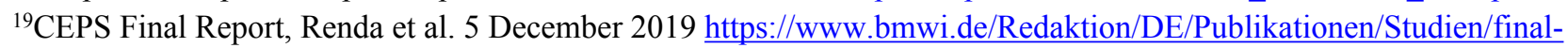
report-oioo-ceps.html
} 
the angle of those innovations that consider European values and objectives. The priorities and values of the EU were clearly spelled out during the settlement of the Von Der Leyen Commission and are the EU Green New Deal and Carbon Neutral Economy. Therefore, the challenge is how to make sure that EU rules can lead the way for European member states to become sustainability champions and, most importantly, how regulations should adapt. This immediately suggests the following question: where does innovation fall in this complex picture of priorities and values?

Professor Karen Yeung (University of Birmingham) had the challenge of kicking-off the debate during the Helsinki Conference addressing this question. She posed the (rhetorical) question whether 'innovation' is something to embrace wholesale. The consequences of an innovation, in fact, may not be wholly positive. There are social innovations and, so to speak, private innovations. On the latter, the claim that innovations are "new ways" and therefore products "function better" and in "a more efficient way" is not always true. In this sense new technologies and digital innovations promise to cut costs and times, but there is the need to reflect on the effects of such innovations, especially whether they are equivalent in all their respects to older instruments. It is wrong to assume that all the innovations are desirable and there is the need to consult with those who are affected or potentially affected by new technologies.

In the debate on responsible innovations, however, another fundamental issue must be raised, and it deals with the assessment of what is 'responsible'. In particular, who is going to determine what a responsible innovation is and what is not? It seems vital to identify what are the channels needed to assess the goodness of an innovation. In fact, a major problem that could appear when declaring an innovation 'irresponsible' deals with the risks related to 'false positives'. For instance, if we think about electricity and how many people got electrocuted before new ways to conduct and manage electricity were invented: what if electricity was declared an irresponsible innovation?

\section{Innovation and Regulation: how to guarantee superior regulatory outcomes?}

There is a policy implication of this way of reasoning about innovation. Arguably, it is about not limiting the IP to the assessment of the impact on innovators, but to consult with those potentially affected by innovations. Hence, another implication is whether innovation also calls for new ways to regulate, in fact innovations, by enlarging the range of impact of new laws and because of their speedy nature, inevitably call for new ways of thinking about regulation. In fact, the panel on IP in Regulatory Practices in Helsinki touched on the issue of regulating innovation. One point raised during the conference was about the concept that rules should anticipate the market's needs. Output oriented regulations should respond to complaints coming from companies and new tech firms that find standards not at pace with new technologies. Thus, the IP as a policy-framing principle aims at outcome-oriented legislation: regulations can and should encourage innovations e.g. on the recycling material industry.

Innovation and regulation, however, are not technical choices. They take place in the real world, where stakeholders have the right to participate. It follows that innovation in regulation also calls for a greater need of engagement. If laws are blamed for not being able to keep up with innovations and changes that happen very fast a continuous consultation with stakeholders should be incentivized in order to correct this distortion. Engagement should then be accompanied with experimental and holistic approaches, review periods of EU regulation, and a more careful focus on communication. For regulation to be a tool of support and not of restriction to innovations these mechanisms of accountability must be enhanced. In fact, the most important implication is certainly the impact on innovation, and this is something to keep in mind throughout the process of design of new rules, but also and most pertinently perhaps regulators should engage and mobilize those potentially affected throughout the process of design.

Citizens engagement is a necessary counterpart of the innovation impact in the design of new regulations. This was a main a take-away point from the Helsinki conference that suggested to consider the innovation 
side of any new proposal, but this should go with the strengthening of mechanisms such as consultation in order to correct the potential distortions that innovations irrespective might have on citizens.

If accountability mechanisms need to be enhanced in order to cope with possible shortcoming of innovations, then how should regulatory design processes adapt to IP? Firstly, innovation is not to be considered the aim of regulation. Helsinki's panellist Veronica Gaffey, Chair of the scrutiny board of the European

Commission, stressed that innovation is a mean to an end and the end is sustainable growth. It is possible to state that the Commission is buying into the IP approach of the Council only within the limits of innovation being a means and not an end. In order to achieve this goal, it is necessary to have evidence-based EU proposed legislation, stakeholder views and hard data, therefore the new EU Commission is pushing for ideas such as: foresight, reduction of administrative burdens and further development of the area of digitalization. Innovation calls for new ways to regulate, in particular mechanisms for agile regulatory policies such as less prescribe-like-regulation should be appraised, together with new ways in designing regulation that given more room for regulatory sandboxes. Strong emphasis is also put on the need for 'less regulation' or to regulate only when necessary. Questions should be raised in the design of new rules such as: do we need this new legislation? What is the objective this law is trying to achieve, what are the options that need to be assessed?

In the words of the Chair of the Regulatory Scrutiny Board the interest of the Commission is to break down an old way of thinking related to Impact Assessment that has previously emphasized the impact of diverse options on the table, in this sense the options where either to do nothing or to do something bureaucratic. The new mindset should be instead on simplification and the questions driving regulation should consider what can be simplified, and what can be digitalized.

How is it possible to assess whether the new tools employed are really innovation friendly? How do we measure innovation and improvement? Measurement and innovation are a central issue that also calls for a reflection on data availability and standardization of measures.

The issue about measurement becomes even more urgent when considering new impact assessments on innovation and the use of parameters of what is 'positive' innovation and what is not. Metrics on innovation are difficult as there are different ways to measure nowadays, but nevertheless the metrics of what is innovation friendly is vital. The issue at stake seems to deal with data and especially with data-availability that is much needed for policy makers to work out the success for a regulation. Gathering data is a collective effort and there is the need for better data collection and standardization, what data regulators are capturing is still not enough - as noted by some of the panellists during the Helsinki Conference- and standardized data should be made transparent, accessible and shared among regulators.

On the need to have more standardized data in order to assess the impact of innovations an interesting example of possible shortcomings was pointed out by the head of 'technologies futures' (NESTA) during the Helsinki Conference. A compelling new technology that is entering a wide number of sectors is Artificial Intelligence (AI). The use of AI, for instance in the judicial sector, is conceived as a mean to enhance access and reduce costs of access to legal aid, however there are no clear and standardized data on what are - and might be - its negative impact. Therefore, data availability is critically connected to innovation and an unavoidable issue that should enter the picture of regulatory policy formulation.

\section{Conclusions}

One way the Commission seems to square the circle among Council's pressures towards the IP, OIOO, the working methods adopted in December, and the controversies on IP versus PP (Precautionary Principle) is, at the moment at least, the following: Innovation is a fundamental perspective endorsed by the Commission, it is not a legal principle (yet). It will not be used to counter precaution and to limit environmental and social 
protection, but quite the contrary: to the extent that the Commission supports Innovation, it does that exactly to achieve the goals of the Green Deal and sustainability in general. Where this is a temerarious proposition or fine political strategy only time will tell.

Innovation is a cornerstone in the regulatory vision of both the Council and the Commission and there seems to be no fracture between the different institutions of the EU. Beyond this shared vision, there are different interpretation and challenges. There are different types of innovation: social innovation can be social in the means and in the ends, or only in the means but not in the ends. Innovations have to be appraised one by one rather than being considered wholesale positive, yet we know that suppressing innovation via bad regulatory choice hinders prosperity and well-being.

The very meaning of regulating for innovation is a territory that the Commission has just started to explore, also because innovation and regulation have been assigned to different DGs and Commissioners in the past and so are now. The Commission embraces innovation as a perspective for regulatory design, but there is no formal endorsement of the IP as foundation of regulatory choice, at least not yet. The RSB will endorse innovation as broad vision about the ultimate goals of regulation.

It is also possible to stress that regulatory offsetting's like OIOO are a political commitment for the new Commission. The challenge is to turn it into methods and techniques, including oversight approaches, that are balanced with IP. Much will depend on the operationalization of OIOO by the Sec Gen and the RSB. Lastly, it seems that the way forward to innovation and regulation is through simplification. Indeed, as mentioned simplification is crucial for regulatory design and innovation. The Commission and beyond Brussels all regulators are challenged by the fact that innovation needs simplification as well as critical thinking about when new rules and standards are really needed and to strike a balance of positive and negative effects of innovation. 